\title{
TAMAN EDUKASI BUNGA DAN TERAPI DI RAWA BELONG
}

\author{
Christine $^{1)}$, Suwandi Supatra ${ }^{2)}$ \\ 1)Program Studi S1 Arsitektur, Fakultas Teknik, Universitas Tarumangara, christinekho79@gmail.com \\ 2) Program Studi S1 Arsitektur, Fakultas Teknik, Universitas Tarumangara, ybhan50@gmail.com
}

Masuk: 14-07-2020, revisi: 31-07-2020, diterima untuk diterbitkan: 24-09-2020

\begin{abstract}
Abstrak
Proses pengembangan suatu kota tidak terlepas dari perkembangan taman hijau RTH dalam kota tersebut. Dimana proses pembangunan suatu kota harus memberikan prioritas terhadap perancangan taman hijau RTH pada setiap wilayah. Ruang terbuka hijau RTH merupakan sebuah kebutuhan dasar yang dibutuhkan masyarakat perkotaan. Taman hijau RTH memiliki 4 fungsi utama, yaitu fungsi ekologis, sosial, ekonomis, dan estetika. Fungsi ekologis, taman merupakan paru-paru dunia dan taman memiliki fungsi untuk meredam kebisingan. Fungsi sosial, taman dapat dijadikan sebagai tempat rekreasi dimana individu dapat berkumpul dan bersosialisasi, fungsi estetika, taman memiliki nilai yang sangat tinggi sehingga dapat dimanfaatkan untuk memperindah kota dan taman juga memberikan unsur ketenangan. Setelah dianalisa RTH Jakarta termasuk kota yang minim akan rekreasi taman hijau RTH. Seperti yang kita ketahui pada zaman sekarang individu lebih sering berinteraksi melalui sosial media, sehingga kehidupan bersosial mulai kehilangan makna. Oleh karena itu, dibutuhkan berupa taman edukasi bunga dan terapi yang berupa komersial, khususnya bagi masyarakat sekitar. Selain itu keberadaan Taman Edukasi Bunga dan Terapi harus bisa memicu interaksi sosial dan sesuai dengan karakter masyarakat sekitar. Terdapat 3 program utama untuk mewujudkan visi yaitu : edukasi bunga, pasar bunga dan kuliner yang dapat dilakukan bersama keluarga ataupun kerabat. Tujuan dari proyek ini agar masyarakat dapat merasakan pengalaman berada di bagunan yang dipenuhi dengan taman hijau RTH serta sebagai tempat pertemuan, bersosialisai dan berkumpul masyarakat.
\end{abstract}

\section{Kata kunci: Sosial; Taman; Tempat ketiga}

\begin{abstract}
The process of building a city is inseparable from the development of parks within the city. Whilst the process of building a city must have a priority towards the designing of parks in each region. One of the cities that has issues with the process of developing parks in Indonesia is Jakarta. Jakarta is classified as a city with minimal park recreation although benefits of having a park recreation might help individuals in overcoming stress. Utilization of green open space in urban areas that parks have 4 main functions namely ecological, social, economic, and aesthetic functions. However, people who live in big cities are faced with a variety of occupations and work demands, therefore individuals need a place of entertainment or recreation, one of which can be a flower garden. As we know at this moment in time, individuals more often interact through social medial, therefore we unconsciously lose the essence of social life. The loss of direct interaction between individuals, resulted in the growth of individualism, narcissism and lack of empathy in humans. With that being said, we need a proper place for the community to refresh their mind, socialize, relax themselves in order to increase interaction between individuals. The facilities needed are in the form of a public educational flower garden and therapy park which is commercial, especially for the surrounding community. In addition, the existence of the Educational Flower Garden and Therapy Park will be able to enhance social interactions and in accordance with the character of the surrounding community.
\end{abstract}

\section{Keywords: Park; Social; Third place}




\section{PENDAHULUAN}

Perkembangan sebuah kota tidak bisa lepas dari perkembangan taman di dalam kota. Setiap kota yang mulai dikembangkan tidak boleh mengesampingkan pembangunan taman di dalam wilayahnya. Jakarta sebagai Ibukota Indonesia, yang sedang berkembang mengalami banyak masalah. Salah satu dari masalah tersebut yang penangannya belum maksimal adalah $\operatorname{stress}^{[2]}$. Selain itu, Jakarta pun sangat memerlukan manfaat dari sebuah taman. Dalam peraturan Menteri Pekerjaan Umum No. 05 Tahun 2008 tentang pedoman Penyediaan dan pemanfaatan Ruang Terbuka Hijau di Kawasan Perkotaan, sebuah taman memiliki fungsi ekologis, sosial, ekonomis, dan estetika yang dapat dirasakan manfaatnya oleh masyarakat kota. Sebagai fungsi ekologis, taman menjadi paru-paru dunia dan juga dapat meredam kebisingan. Sebagai fungsi sosial, taman merupakan rekreasi dan tempat bermain bagi masyarakat kota. Sebagai fungsi estetika, taman meningkatkan kenyamanan dan memperindah lingkungan kota.

Namun, seperti yang kita tahu bahwa terdapat beberapa masalah dimana kehidupan di kota yang penuh dengan kesibukan sehingga memaksa masyarakat memilih untuk melakukan semua hal serba cepat. Permasalahan yang muncul diantaranya adalah kurangnya waktu bersosialisasi dan beraktivitas fisik. Orang- orang mulai mencari hiburan atau tempat berkumpul di pusat perbelanjaan (Mall) yang sebenarnya kurang tepat untuk menjadi tempat bersosialisasi, dimana didalamnya tidak ada interaksi antar sesama. Masyarakat lebih sering berinteraksi melalui media sosial seperti Instagram, Twitter, Youtube dan lainnya, sehingga kehidupan bersosial mulai kehilangan makna. Hilangnya interaksi secara langsung antar sesama individu, membuat manusia mulai hidup secara individualis, oleh karena itu masyarakat membutuhkan sebuah tempat dimana mereka dapat melepas penat, menghilangkan stress dan berinteraksi dengan sesama.

Taman adalah merupakan suatu sumber kehidupan yang berada di sekitar manusia. Fungsi dari bagian tubuh tanaman sangat berguna bagi manusia agar dapat bertahan hidup, seperti yang kita ketahui bahwa tanaman dapat meningkatkan kadar oksigen. Selain membuat udara sejuk, dan pelindung sinar matahari salah satu cara menghilangkan stress yaitu bersentuhan dengan tanaman, contohnya seperti merawat tanaman, kerajinan tangan, mengolah menjadi obatobat an dan kecantikan. Dengan adanya sentuhan terhadap tanaman, maka antar individu dapat bertemu dan memiliki kesamaan motivasi, sehingga tercipta kehidupan masyarakat kota yang lebih sehat dan terwujud ruang ketiga (third place), sebagai "social-interactive".

\section{KAJIAN LITERATUR}

\section{Open Architecture}

Open Architecture merupakan sebuah sistem terbuka yang mampu beradaptasi dengan kepentingan terpilih dan menjadi kesempatan untuk menciptakan sebuah platform arsitektur yang dapat dikombinasikan dengan berbagai macam keadaan dan kondisi masyarakat ${ }^{[9]}$.

Open Architecture membahas mengenai The Third Place didalamnya menjelaskan mengenai sebuah program yang didukung dengan program-program lain yang mampu melayani kebutuhan masyarakat kota modern yang menuntut kehidupan serba cepat, dinamis, dan efisien, sehingga masyarakat kota lebih bersifat humanis dan produktif. Open Architecture merupakan the third place bagi masyarakat kota, yang berfungsi sebagai ruang antara seperti ruang yang bukan tempat tinggal dan bukan tempat kerja atau sekolahan.

\section{Third Place}

Third place menurut Ray Oldenburg (1999) yang menyatakan bahwa Third Place adalah merupakan tempat dimana orang menghabiskan waktu di antara tempat tinggal (first place) dan tempat kerja (second place) yang bertujuan untuk orang yang ingin mengobati stress, kesepian, dan keterasingan. Pengertian dari Third Place adalah suatu tempat yang bisa 
dijadikan tempat berlindung sementara dari kejenuhan, kecemasan, depresi dan lainnya. Tidak hanya dijadikan tempat untuk melarikan diri, tetapi dimana orang akan ber santai dan terasa terhibur dan juga mendapatkan ketenangan di dalamnya.

\section{Taman}

Laurie (1986:9) mengemukakan bahwa asal mula pengertian kata taman (garden) dapat ditelusuri pada bahasa Ibrani gan, yang berarti melindungi dan mempertahankan; menyatakan secara tidak langsung hal pemagaran atau lahan berpagar, dan oden atau eden, yang berarti kesenangan atau kegembiraan. Dari batasan tersebut dapat diambil pengertian sebagai berikut:

- Taman merupakan wajah dan karakter bahan atau tapak, berarti bahwa menikmati taman mencakup dua hal, yaitu penampakan visual, dalam arti yang bisa dilihat dan penampakan karakter dalam arti apa yang tersirat dari taman tersebut. Mungkin dari ceritanya, gambar yang teraplikasi, nilai-nilai yang terkandung dari taman tersebut.

- Taman mencakup semua elemen yang ada, baik elemen alami (natural), elemen buatan manusia (artificial), bahkan makhluk hidup yang ada didalamnya, terutama manusia.

Menurut Djamal (2005), taman adalah sebidang tanah terbuka dengan luasan tertentu di dalamnya ditanam pepohonan, perdu, semak dan rerumputan yang dapat dikombinasikan dengan kreasi dari bahan lainnya. Umumnya dipergunakan untuk olahraga, bersantai, bermain dan sebagainya. Secara umum terdapat perbedaan pengertian antara taman sebagai landscape dan taman sebagai garden, yaitu bahwa taman (landscape). Elemen tamannya lebih banyak didominasi oleh elemen alami, sedangkan (garden) elemennya lebih didominasi oleh elemen buatan manusia (artificial) dan dalam luas yang lebih terbatas (Suharto, 1994:5).

\section{Rekreasi}

Rekreasi merupakan kegiatan yang dilakukan uuntuk penyegaran kembali jasmani dan rohani seseorang ${ }^{[2]}$. Merupakan sebuah aktivitas yang dilakukan diwaktu senggang (leisure time). Leisure berasal dari Bahasa Latin "licere" yang berarti diperkenalkan atau menyegarkan kembali. Kegiatan yang umum dilakukan adalah pariwisata, bermain, dan hobi dan biasanya yang dilakukan untuk melepas penat. Menurut Krauss (1984) yang mengatakan bahwa rekreasi adalah aktivitas atau pengalaman yang diperoleh atau dilakukan dalam waktu senggang dan biasanya dilaksanakan di waktu senggang. Berdasarkan kegiatannya, rekreasi dapat dibagi menjadi 4 jenis, yaitu physical recreation, social recreation, cognitive recreation dan environmental-related recreation.

\section{Meurut Krauss (1984)}

Aktivitas atau pengalaman yang diperoleh atau dilakukan dalam waktu senggang dan biasanya dilaksanakan di waktu senggang. Berdasarkan kegiatannya, rekreasi dapat dibagi menjadi 4 jenis, yaitu physical recreation, social recreation, cognitive recreation dan environmentalrelated recreation.

\section{Edukasi}

Secara etimologis, edukasi berasal dari kata lain yaitu educare yang artinya "memunculkan", "membawa", "melahirkan". Dalam pengertian secara luas edukasi adalah setiap tindakan atau pengalaman yang memiliki efek formatif pada karakter, pikiran atau kemampuan fisik dalam individu. Pendidikan dan edukasi memiliki pengertian yang berbeda, pendidikan adalah pengubahan sikap dan tata laku seseorang atau kelompok yang dalam usaha mendewasakan manusia melalui upaya pengajaran dan latihan, proses, pembuatan, dan cara mendidik (KBBI. 1990). Sedangkan pengertian edukasi adalah upaya dari subjek terhadap objek untuk mengubah cara memperoleh dan mengembangkan pengetahuan menuju cara tertentu yang diinginkan oleh subjek (Suroso, Rendra. 2004). 
Edukasi memiliki konsep dasar yang telah mengacu pada proses, yaitu instruction, teaching dan learning. Berdasarkan tujuan kegiatannya, terdapat lima jenis edukasi, salah satunya adalah edukasi lingkungan. Edukasi lingkungan adalah sebuah proses pembelajaran dan pendidikan yang diberikan oleh narasumber yang kredibel kepada peserta, dimana peserta belajar tentang segala hal yang berkaitan dengan lingkungan alam bumi ini, seperti teknik menanam pohon yang baik serta cara merawatnya.

\section{Rekreasi Edukasi}

Salah satu jenis bentuk rekreasi adalah pariwisata. Menurut A.J Burkart dalam Damanik (2006), pariwisata adalah perpindahan orang untuk sementara dan dalam jangka waktu pendek ke tujuan- tujuan di luar tempat dimana mereka biasa hidup dan bekerja dan kegiatan-kegiatan mereka selama tinggal di tempat-tempat tujuan. Kegiatan dalam suatu perjalanan pariwisata disebut wisata. Oleh karena itu, banyak muncul istilah wisata sejarah, wisata budaya, wisata alam, wisata edukasi, dan jenis wisata lainnya.

Berdasarkan pada fungsi rekreasi dan edukasi, maka pembahasan lebih difokuskan pada kegiatan wisata edukasi. Di Indonesia, terdapat empat jenis wisata edukasi, salah satunya adalah wisata edukasi agrobisnis. Wisata edukasi yang berbisnis pada pendidikan agro atau pertanian dan peternakan yang juga merupakan bisnis dari suatu perusahaan maupun perorangan.

\section{Taman Vertikal}

Merupakan suatu cara/ teknik pertanian yang dilakukan secara vertikal, dimana memiliki skala yang cukup besar di lingkungan perkotaan, dimana menggunakan bahan-bahan daur ulang serta teknik greenhouse seperti hidroponik ${ }^{[6]}$.

Berikut ini adalah beberapa teknologi/ cara penanaman yang sesuai, yaitu:

- Green House, dimana menggunakan penutup yang terbuang dari bahan cukup transparan, ditujukan untuk menjaga temperatur di dalamnya.

- Aeroponic, sistem penanaman yang tidak menggunakan tanah maupun air, dimana akar tanaman tersebut diletakan didalam ruang kosong dan bertujuan agar akar mudah untuk menangkap oksigen di sekitarnya, pada bagian bawah diberi sedikit air untuk kebutuhan tanaman.

- Hydroponic, sistem penanaman dimana menggunakan nutrisi-nutrisi yang berada di dalam air sepenuhnya/ tidak menggunakan tanah. Dimana memiliki kemudahan seperti mudah dalam mengontrol nutrisi di dalam air, mengurangi polusi nutrisi yang terlepas ke udara, menghindar dari hama yang biasanya tinggal didalam tanah.

- Phytoremediation, merupakan suatu sistem yang digunakan untuk mendaur ulang air, dimana dari black water - grey water - air yang layak digunakan.

\section{METODE}

Metode perancangan yang digunakan sebagai berikut, 1 . Mencari isu dan latar belakang dari kawasan (kebudayaan); 2. Menganalisa kebutuhan dan permasalahan dari kawasan yang dipilih; 3. Menganalisa kebutuhan masyarakat apa yang sesuai; 4. Penyelesaian secara arsitektur; 5. Melakukan studi preseden; 6. Penyusunan program; 7. Analisis aktivitas dan kebudayaan; 8. Analisi program utama dan program pendukung; 9. Proses perancangan ${ }^{[11]}$.

\section{DISKUSI DAN HASIL}

Taman Edukasi Bunga \& Terapi di Rawa Belong berlokasi di Jl. RawaBelong, Kec. Sukabumi Utara, Jakarta Barat. Fungsi dalam proyek ini yaitu Area workshop, Area proses bercocok 
tanam, Taman Publik, dan Ruang Komunal. Keseluruhan bangunan dengan luas $4.000 \mathrm{~m}^{2}$ terbangun diatas tanah seluas $2.000 \mathrm{~m}^{2}$

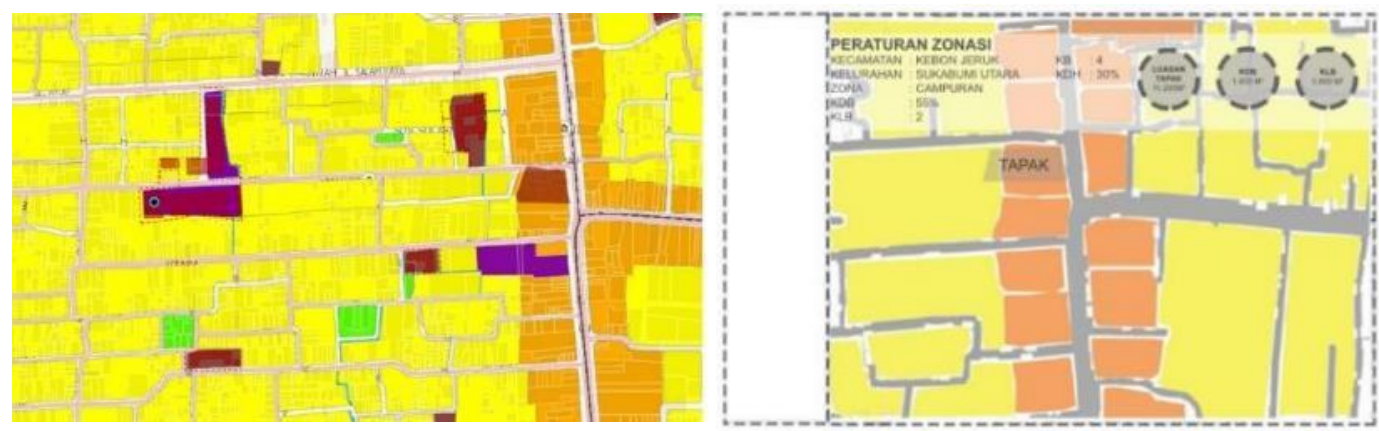

Gambar 1. Zonasi Lokasi dan Sekitarnya. Sumber : Dokumentasi Pribadi, 2020

$\begin{array}{llll}\text { Kecamatan } & \text { : Kebon Jeruk } & \text { KB } & : 4 \\ \text { Kelurahan } & \text { : Sukabumi Utara } & \text { KLB } & : 2 \\ \text { Zona } & \text { : Campuran } & \text { KDH } & : 30 \% \\ \text { Id Subblok } & \text { :001. C. } 1 . \text { B } & \text { KDB \& KTB } & : 50 \%\end{array}$

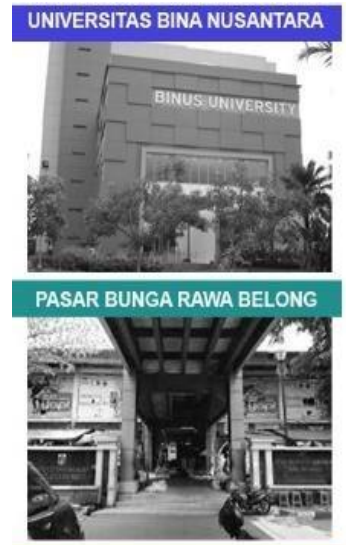

TPS SAMPAH ANORGANIK

III 17T

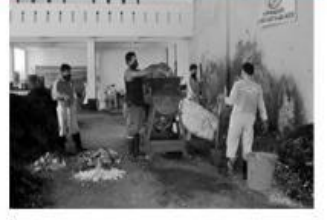

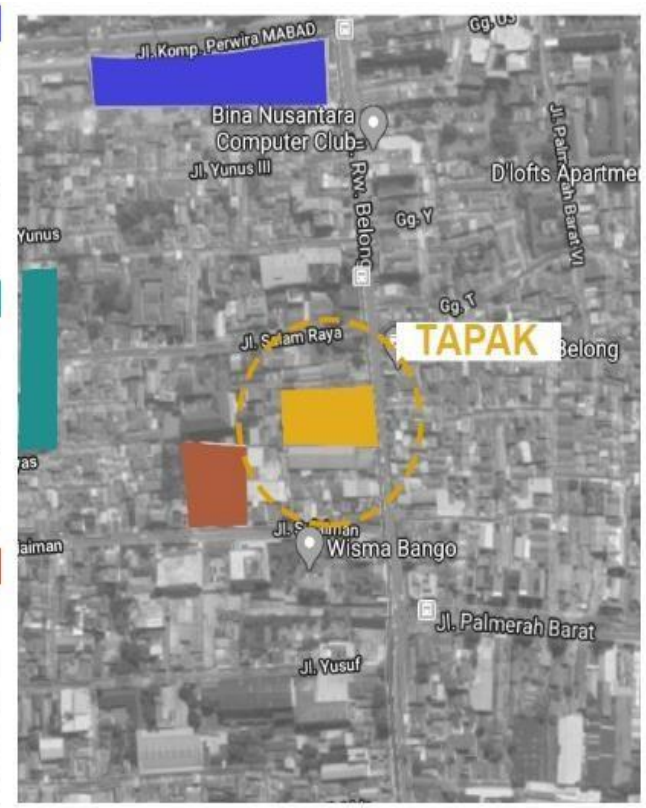

Gambar 2. Analisa Sekitaar Tapak.

Sumber : Dokumen Pribadi, 2019

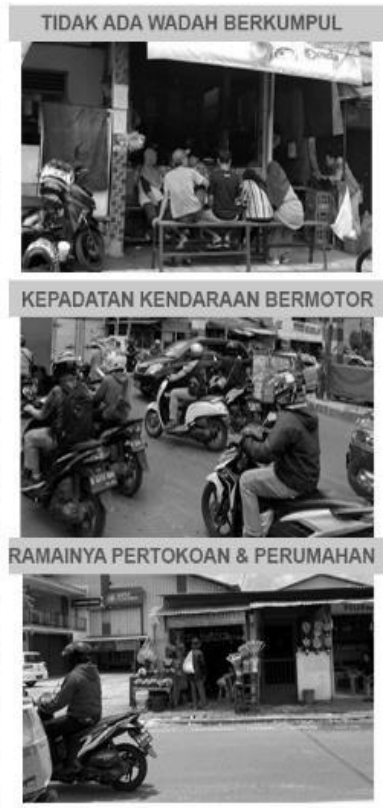

Hasil analisa kawasan Sukabumi Utara, tapak terpilih sangat cocok untuk program third place dan tapak terletak diantara perumahan, universitas dan perkantoran. Sehingga sering kali dilewati dan dapat menjadi tempat persinggahan. Selain itu, tapak sangat strategis dan ramai akan transportasi umum sehingga mempermudah dalam pencapaian ke tapak. Dengan program utama dari proyek ini adalah sebuah Taman Edukasi dan beberapa fasilitas pendukung, seperti : café, dan restoran. Untuk fasilitas pendukung lainnya seperti hunian dan masyarakat yang berasal dari sekitar tapak (kos-kosan, hunian, dan apartemen) yang dapat meningkatkan taraf hidup dan ekonomi warga setempat. 

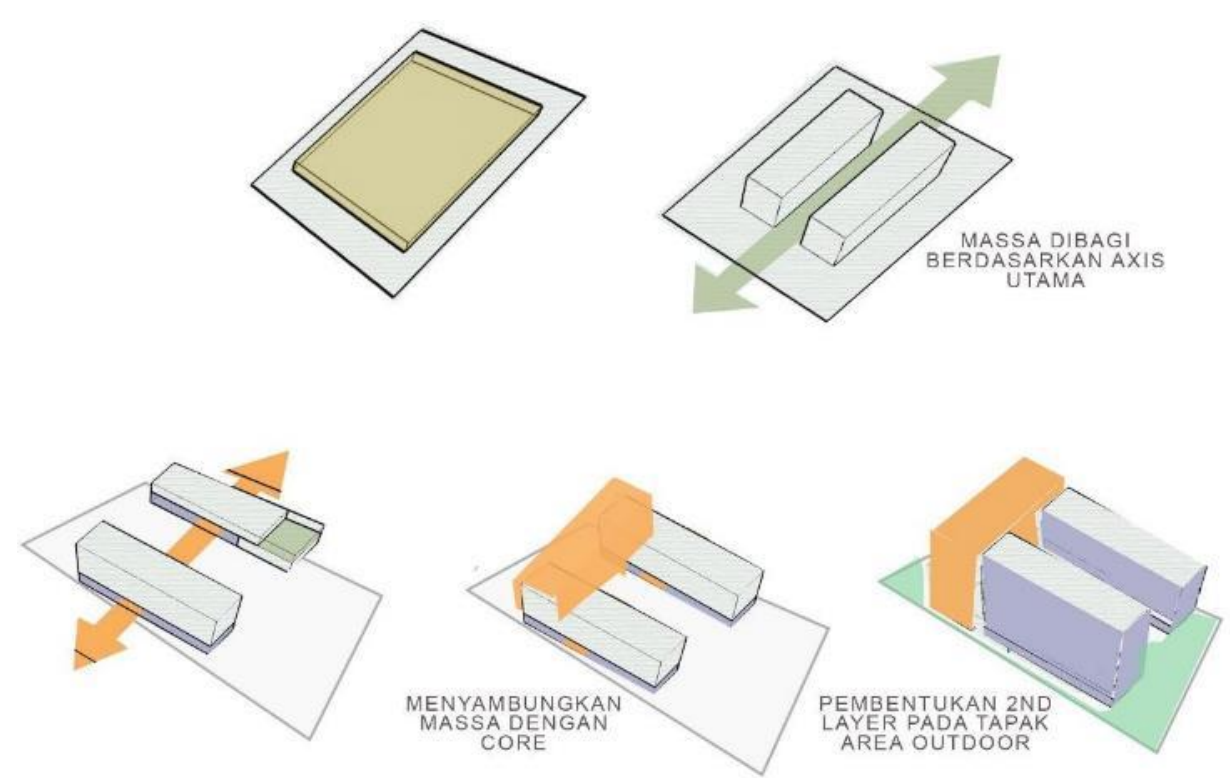

Gambar 3. Design Scheme

Sumber : Dokumen Pribadi, 2020

Dari peraturan- peraturan yang telah ditetapkan pada tapak dan melakukan berbagai analisis tentang pergerakan manusia, akses yang biasa dilalui, dan konsep gubahan massa yang berifat terbuka dan umum.

Berikut gambaran visual dari proyek ini.

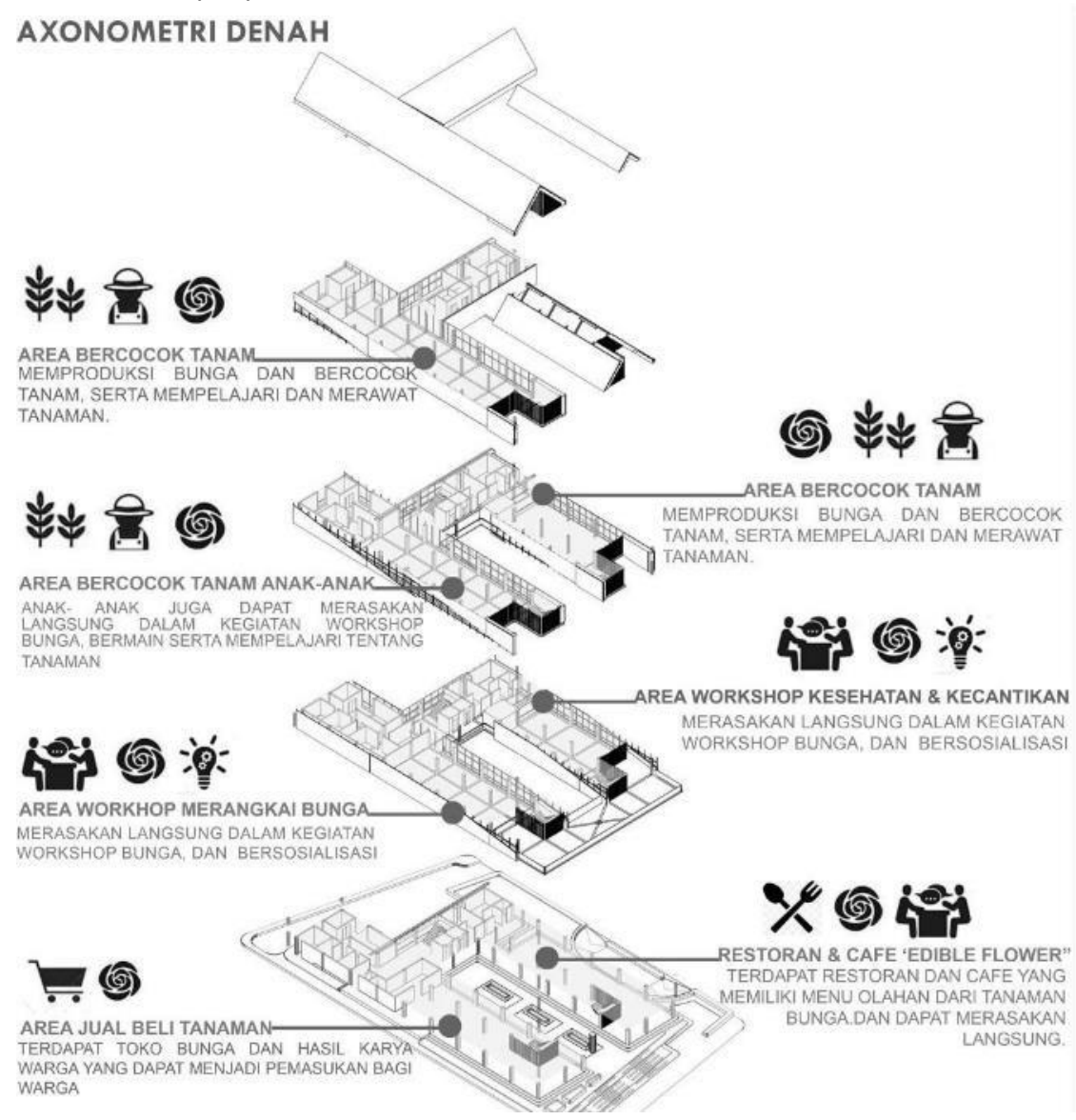

Gambar 4. Exploded Denah

Sumber : Dokumentasi Pribadi, 2020 
Blokplan proyek sebagai berikut.

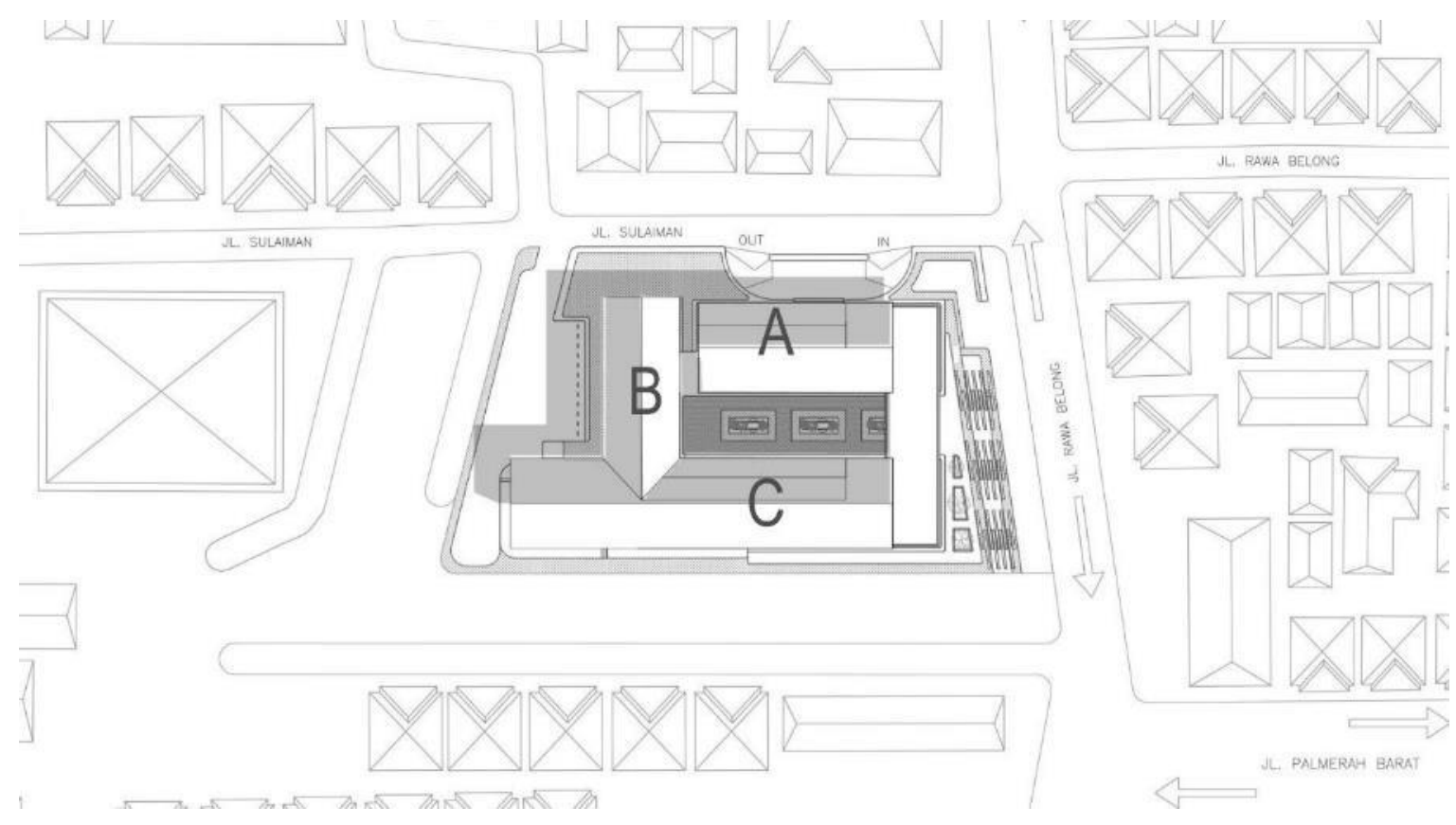

Gambar 5. Blokplan- Atap Bangunan

Sumber : Dokumentasi Pribadi, 2020

Denah Lt. Dasar proyek sebagai berikut.

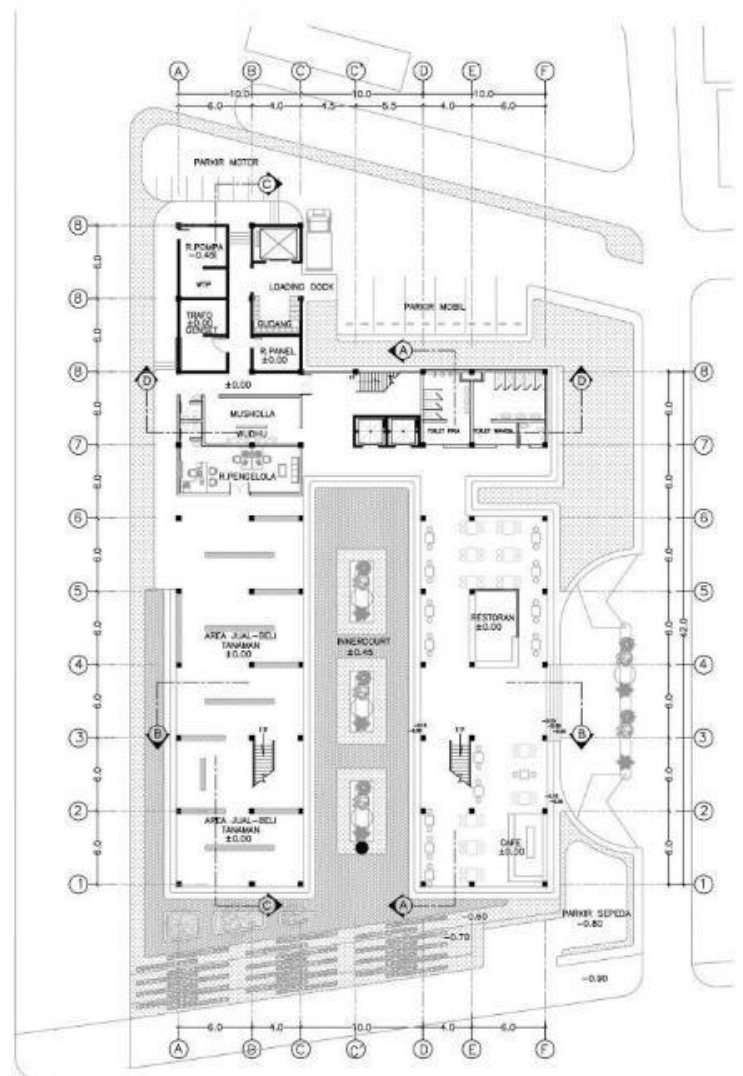

Gambar 6. Denah Lantai Dasar

Sumber : Dokumentasi Pribadi, 2020 
Pada denah lantai dasar memperlihatkan bagaimana sirkulasi pejalan kaki yang masuk ke dalam tapak dan juga sebaliknya. Dengan pemisahan akses kendaraan dan pejalan kaki, membuat tapak menjadi lebih menghargai pejalan kaki dan tidak ada crossing di dalam tapak.

Tampak dan Potongan proyek sebagai berikut.

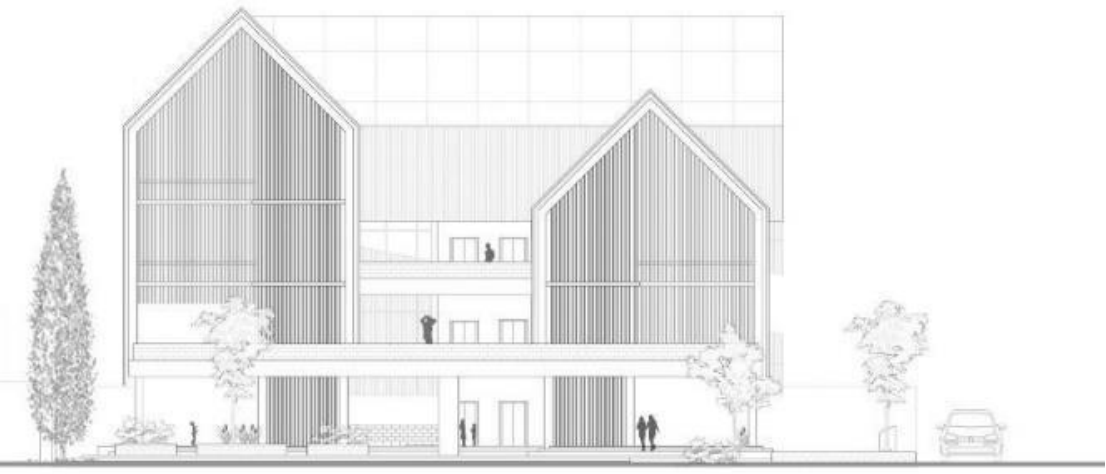

TAMPAK DEPAN

SKALA 1:200

Gambar 7. Tampak Depan

Sumber: Dokumentasi Pribadi, 2020

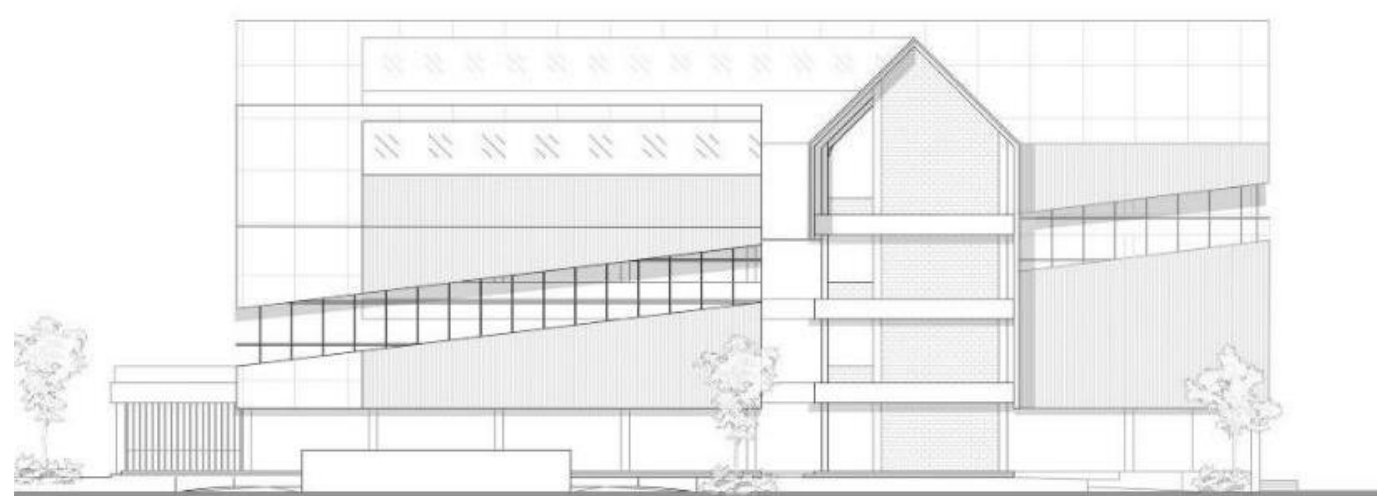

\section{TAMPAK KANAN}

SKALA 1:200

Gambar 8. Tampak S. Kanan

Sumber: Dokumentasi Pribadi, 2020 


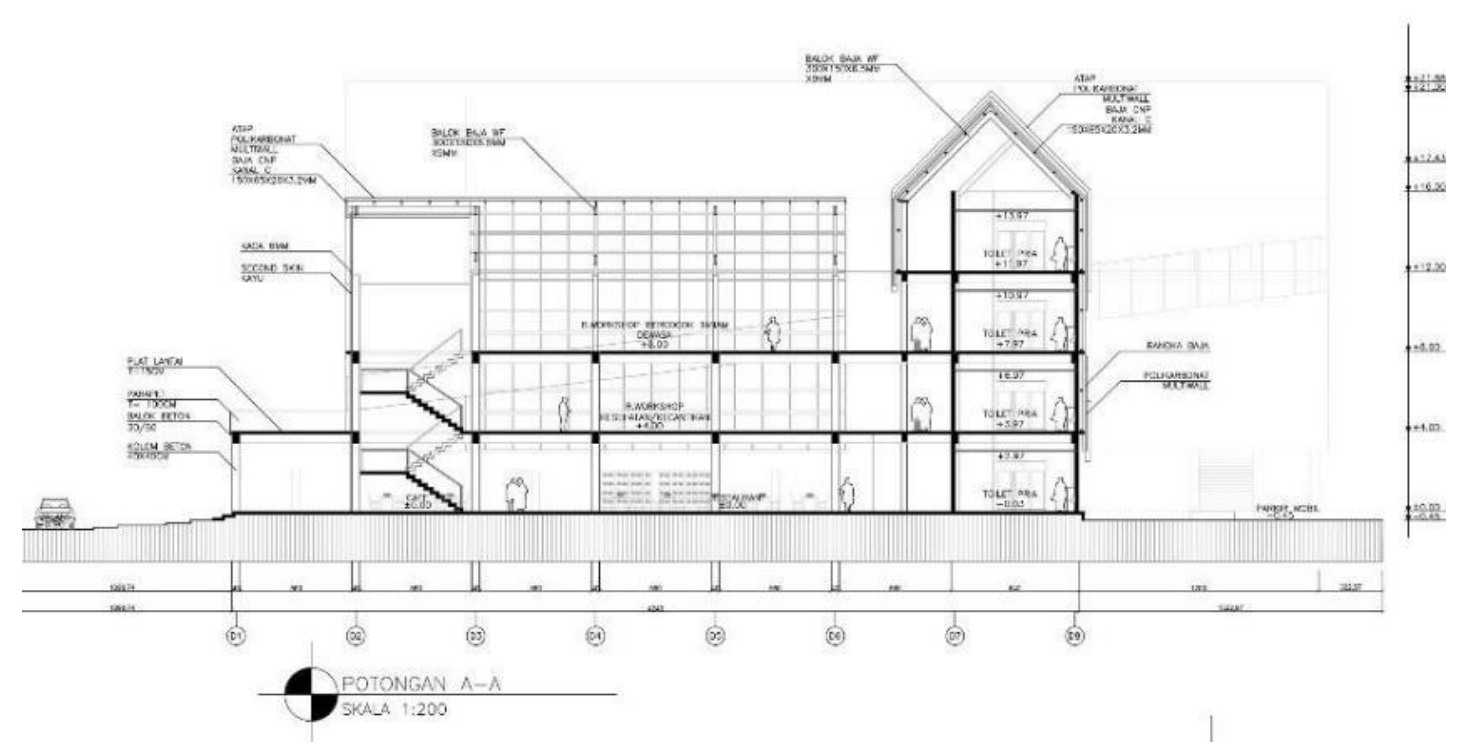

Gambar 9. Potongan A- A

Sumber: Dokumentasi Pribadi, 2020

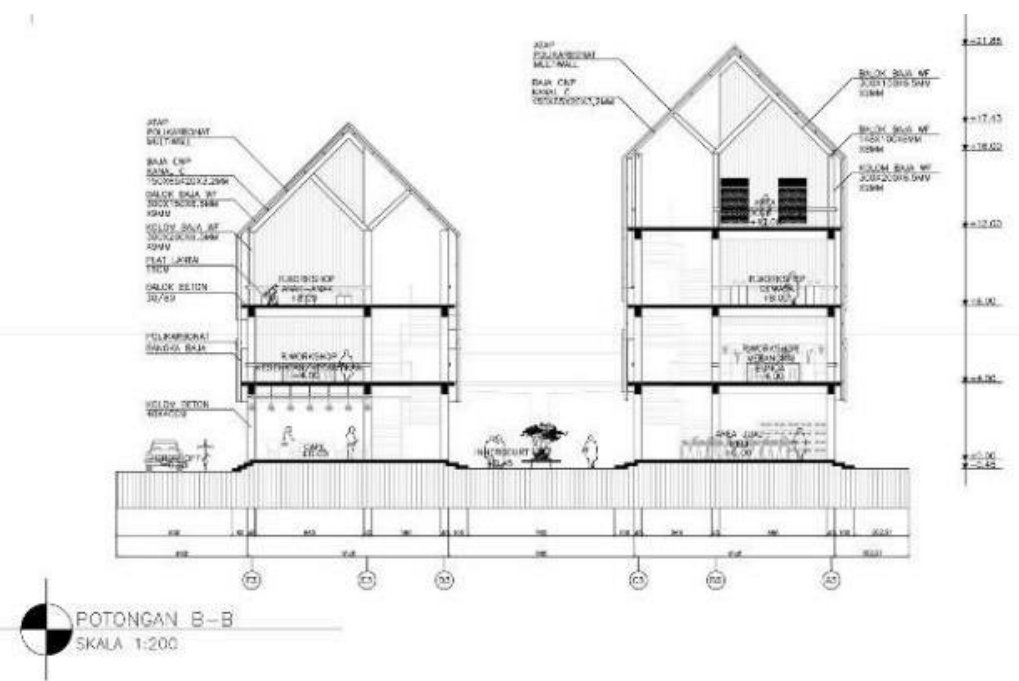

Gambar 10. Potongan B- B

Sumber: Dokumentasi Pribadi, 2020

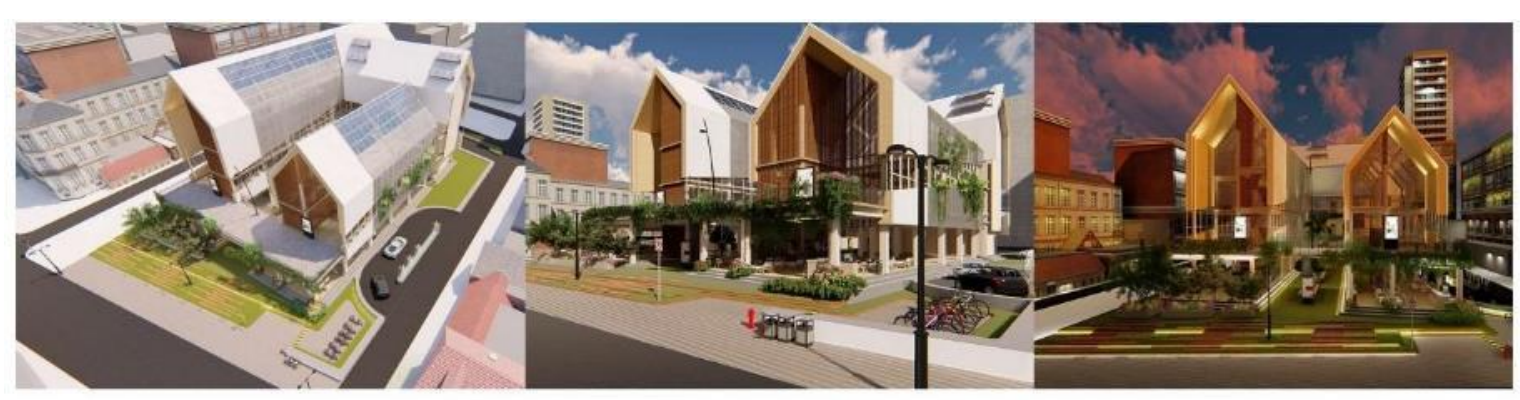

Gambar 11. Eksterior

Sumber : Dokumentasi Pribadi, 2020 


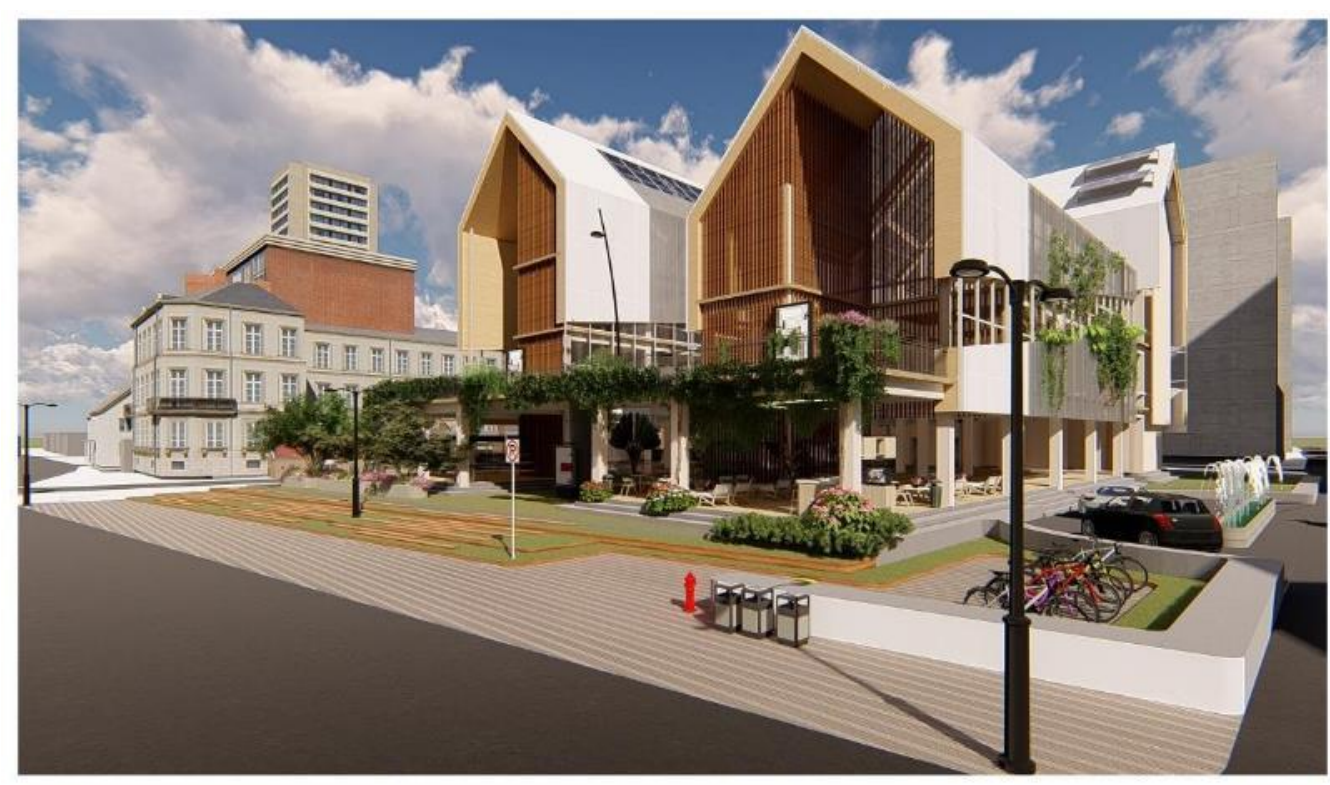

Gambar 12. Perspektif Eksterior

Sumber : Dokumentasi Pribadi, 2020

\section{KESIMPULAN DAN SARAN}

Proyek Taman Edukasi Bunga dan Terapi di Rawa Belong, yang terletak di jl. Rawa Belong, Jakarta Barat ini diharapkan dapat bermanfaat bagi lingkungan sekitar, terutama masyarakat sekitar yang mengalami isu dalam kawasan tersebut. Dimana melalui program yang telah ditetapkan akan mempengaruhi dan meningkatkan potensi dan inovasi masyarakat. Selain itu, dapat meningkatkan kepercayaan diri, relasi antar individu dan juga kreativitas.

Dalam merancang proyek ini perlu diperhatikan beberapa, seperti sirkulasi, kebutuhan program berdasarkan kebudayaan dan kebiasaan masyarakat sekitar. Hal tersebut mempengaruhi keefektivitasan, kenyamanan, juga suasana ruang ketiga ( third place) yang dapat merelaksasikan diri dan pikiran masyarakat, bersantai dan juga bersosialisasi.

\section{REFERENSI}

Cooper, C.L. \& Davidson, R. (1991). Personality and stress: individual differencesin the stress process. NewYork: John Wiley and Sons Ltd.

Goldfried, M.R. \& Davidson, G.L. (1976). Clinical behavior therapy. New York: Holt Rinehart and Winston.

Kurniawan, M.S. (2009). Pengertian Relaksasi, (Online), (http://mr.kurniawan. pengetahuan. blogspot. com/2009/06/ pengertian. relaksasi. html).

Morby, Alice. 17 Desember 2015. Epicentro Fills Sao Paulo Flower Shop with Vintage.

Mukhtar. (2013). Metode penelitian deskriptif kualitatif. Jakarta: GP Press Group.

Neufert, E. (2002). Data Arsitek Jilid 1 dan 2. Jakarta: Penerbit Erlangga

Oldenburg, R. (1999). The Great Good Place: Cafés, Coffee Shops, Bookstores, Bars, Hair Salons, and Other Hangouts at the Heart of a Community. United States: Marlowe.

Subagio, J. dan Sherine Bangsa Wibawa. 24 Juni 2019. Jakarta Masih Kekurangan Ruang Terbuka Hijau, Ini Penjelasan Ahli.

Tjahjono, G. (2000). Metode Perancangan Suatu Pengantar untuk Arsitek dan Perancang. Depok: Universitas Indonesia. 